\title{
Propos sur La Dernière année
}

About La Dernière année

\section{Philippe Vilain}

\section{OpenEdition}

\section{Journals}

Édition électronique

URL : https://journals.openedition.org/recherchestravaux/2782

DOI : 10.4000/recherchestravaux.2782

ISSN : 1969-6434

Éditeur

UGA Éditions/Université Grenoble Alpes

\section{Édition imprimée}

ISBN : 978-2-37747-241-3

ISSN : 0151-1874

\section{Référence électronique}

Philippe Vilain, «Propos sur La Dernière année », Recherches \& Travaux [En ligne], 97 | 2020, mis en ligne le 12 novembre 2020, consulté le 05 juillet 2021. URL : http://journals.openedition.org/

recherchestravaux/2782 ; DOI : https://doi.org/10.4000/recherchestravaux.2782

Ce document a été généré automatiquement le 5 juillet 2021.

(c) Recherches \& Travaux 


\title{
Propos sur La Dernière année
}

\author{
About La Dernière année
}

\author{
Philippe Vilain
}

\section{1.}

1 Tous mes textes présentent une expérience du deuil, du deuil filial (La Dernière année) ou du deuil amoureux (Le Renoncement, L'Été à Dresde, Paris l'après-midi, Faux-père, La Femme infidèle, Une idée de l'enfer ou La Fille à la voiture rouge $\left.{ }^{1}\right)$. Qu'il s'agisse de récits de fin de vie ou de fins d'amour, il s'agit toujours du deuil d'une histoire, d'une forme de consolation et d'oraisons funèbres modernes. Il s'agit toujours d'un narrateur retraçant les derniers jours de la vie d'un proche, et récitant les étapes d'une mortification annoncée - signes annonciateurs d'une maladie ou d'une lassitude conjugale, dégradation de l'intégrité psychique d'un individu ou d'un couple, désagrégation et vieillissement de la mémoire du lien, crépuscule de la raison ou de la mémoire affective, déchéance physique ou renoncement au désir physique, prise d'acte de décès de l'amour, veillée funèbre par l'écriture au travers d'une structure temporelle du mourir comme d'une poétique du deuil. Écrire, ce n'est peut-être pas tant vouloir faire le deuil, que rejouer une infinie cérémonie des adieux.

\section{2.}

2 C'est dans La Dernière année, mon deuxième texte paru en 1999, que le pari de décrire l'imminence de la mort est le plus grand. Lorsque j'ai commencé d'écrire ce texte, mon père était encore à l'hôpital. Je voulais saisir les derniers moments de sa vie, le photographier en train de mourir, scanner ce transformateur fantastique qu'est la mort, sauver la mémoire de mon père dans une alternance de souvenirs et de visites à l'hôpital, comme si l'écriture était pour moi le seul moyen d'avoir prise sur sa mort, d'accompagner mon père un peu. Écrivant dans l'urgence, il n'était pas question pour moi de reconstituer le passé de mon père de façon exhaustive et panoramique. Par ailleurs, la dégradation de son état de santé rendait aléatoire l'évocation d'un passé figé. Le présent de l'écriture s'imposait pour faire émerger les non-dits et laisser se 
télescoper librement, dans un va-et-vient entre la dernière année et les années de vie du père, les fulgurances de souvenirs, les flashs de l'histoire familiale et la vision du corps hospitalisé de mon père. L'écriture du présent prend en charge le processus diachronique de l'existence : faire cesser une histoire pour prolonger son récit. Ce texte se présente comme une sorte de journal, que j'achève avant la mort programmée de mon père. Le texte devait rendre la dimension ontologique de l'écriture : dire l'agonie de mon père, c'était saisir l'être qui s'en va et celui qui reste, saisir les premiers jours où je deviens orphelin de mon père; décrire sa disparition, c'était décrire les moments de ma renaissance en tant qu'homme cessant d'être un fils.

3.

3 Mais sa mort était aussi le prétexte d'écrire autre chose, de révéler une souffrance de jeunesse : l'alcoolisme de mon père - cela même, ces mots que je m'étais gardé pendant tout ce temps de formuler. Il me fallait absolument écrire cela un jour, dire tout cela sans me faire plaindre, sans tomber dans le misérabilisme facile et le pathétique, raconter l'histoire de mon père, cet homme au destin contrarié par ses origines sociales, qui avait l'esprit littéraire et aurait voulu être chirurgien, mais qui s'était lassé de l'existence, de l'angoisse de vivre que l'alcool avait su tempérer. Pour le dire de façon amusante, je voulais écrire sobre sur l'alcoolisme de mon père, mettre à distance tout lyrisme libérateur.

4 Mais révéler ce secret n'était pas si facile, même si la mort de mon père, sans rien justifier, légitimait cette révélation. C'était une révélation difficile pour mon entourage, ma mère surtout. Moi, cela ne m'importait pas. Quand on écrit, il ne faut pas se soucier de ce que pensera le lecteur. D'ailleurs, je n'avais le sentiment de m'exhiber (alors que j'ai ce sentiment de m'exhiber et d'être impudique quand je suis en dehors de mon art et fais la promotion d'un livre), mais de m'exposer. À quoi ? Dire la mort, c'est encore se risquer à ne rien dire, à manquer sa cible. Parler de soi, de sa vie, de ses drames, c'est risquer d'être jugé par le lecteur, c'est être menacé par l'ombre de la corne de taureau de Michel Leiris : écrire sur soi est une forme de tauromachie symbolique.

4.

5 Il fallait également que je comprenne "pourquoi je n'ai pas conservé la moindre rancune envers un homme qui a gâché mes premières années » : c'est en écrivant que j'ai pris conscience de la complicité qui m'avait toujours uni à mon père. Cette avancée vers la mort de mon père correspondait paradoxalement à ma naissance en tant qu'écrivain, puisqu'il s'agissait de l'écriture de mon deuxième texte. Je me disais que s'il n'avait pas bu, je n'aurais peut-être pas eu un lien aussi fort avec lui et si je n'avais pas souffert, à ses côtés, avec lui et non contre lui, je ne serais sans doute jamais devenu écrivain. Quelque part, son alcoolisme, où s'origine mon écriture, est mon merveilleux malheur. 
5.

6 Tous mes textes s'articulent autour d'une scène fatale, cruciale, qui fait basculer l'histoire vers sa fin : une scène d'aveu le plus souvent, une scène de non-présentation (le professeur ne présente pas la coiffeuse Jennifer à ses collègues dans Pas son genre), une scène originaire, fondatrice, constitutive de mon mythe personnel dans La Dernière année (une nuit, ma mère me réveille pour humilier mon père devant moi ; mon père, ivre, dont le front est ensanglanté, sort du commissariat après une bagarre). C'est Jacques Lecarme qui a le mieux analysé cette scène :

Pourquoi une histoire si dure et si singulière dans ses déterminations sociales prend-elle une résonance universelle et, malgré tant de pudeur et tant de discrétion, un pathétique profond ? Freud, il y a un siècle, avait déjà dit que rien ne perturbe plus un enfant que la chute ou la déchéance de la figure de son père, et il en avait indiqué, pour son propre cas, les circonstances, beaucoup moins dramatiques. Mais c'est la Bible qui raconte la vraie scène originaire: Noé, inventeur de la viticulture, s'enivre au point de se dénuder : l'un de ses fils, qui aura vu sa nudité, se verra maudit à jamais, les deux autres couvriront d'un manteau le corps honteux d'un père humilié. Une scène analogue s'est jouée dans d'innombrables vies, mais le premier récit exemplaire en est donné aujourd'hui. Une nouvelle figure œdipienne peut se deviner ici: le fils ne se désolidarisera jamais du père, sera pour lui un père et une mère aimants, mais il s'en voudra de n'avoir pas su aimer sa mère : celle-ci ne pouvait aimer le père buveur, mais ne pouvait non plus l'aider à se guérir de cette maladie. Et si l'alcoolisme n'était pas, comme la tragédie grecque, une tragédie universelle ${ }^{2}$ ?

6.

7 Écrire sur la mort de son père, c'est écrire sur la mort de tous les pères. Toute écriture autobiographique recèle en elle une dimension universalisante. Toute histoire d'un deuil transpersonnalise sa douleur, autruifie ses morts. L'intime permet d'accéder à l'« universel singulier » dont parlait Sartre, à l'« humaine condition » que Montaigne évoquait. Mes propres souvenirs appellent par identification les souvenirs du lecteur comme l'indique Michel Butor à propos de La Règle du jeu de Michel Leiris : "Lorsqu'il fouille ses souvenirs, ce sont les nôtres qu'il réveille, non point identiques, bien sûr, mais comparables. En grattant l'écorce de son moi, c'est un "nous" qu'il découvre audelà de sa solitude ${ }^{3}$ ». On se souviendra encore, pour illustrer ce propos, du célèbre prologue autojustificatif de Simone de Beauvoir dans La Force de l'âge: "On me dira peut-être que ce souci ne concerne que moi; mais non, Samuel Pepys ou JeanJacques Rousseau, médiocre ou exceptionnel, si un individu s'expose avec sincérité, tout le monde, plus ou moins, se trouve mis en jeu. Impossible de faire la lumière sur sa vie sans éclairer, ici ou là, celle des autres ${ }^{4} »$. On ne peut pas écrire le deuil sans transcender sa souffrance.

8 La voix orpheline du je qui dit et donne la mort par l'écriture, qui porte la mort en lui, qui charrie avec lui toute une poétique et une rhétorique du deuil, c'est la voix singulière d'une mort collective qui parle en nous et nous parle à tous : c'est la voix d'un je transcendant, impersonnel ou transpersonnel. La voix d'Annie Ernaux qui raconte la mort de son père est ma propre voix, la voix de Philippe Forest qui pleure sa fille dans L'Enfant éternel est ma propre voix qui pleure l'enfant que je n'ai pas eu. C'est la voix fidèle d'un anonymat dans lequel chacun peut se projeter et se personnifier, 
s'exprimer et s'identifier. La voix poétique de l'orphelin est, en ce sens, toujours anonyme.

7.

9 Je dois revenir un instant sur le genre de La Dernière année. Lorsque j'ai rendu le texte à mon éditeur d'alors, Philippe Sollers, je n'avais précisé aucune mention quant au genre de ce texte, qui n'était ni vraiment un journal, ni vraiment un récit, encore moins un roman : à mes yeux, c'était un texte, rien de plus, rien de moins. Mais quelle ne fut pas ma surprise lorsque, effectuant mon service de presse chez Gallimard, je me suis aperçu que figurait sur la couverture la mention "roman ». J'ai immédiatement demandé à mon éditeur de supprimer cette mention s'il devait y avoir une réédition. Il m'était impossible d'assumer le fait qu'il s'agisse d'un roman. Mon éditeur a accepté en s'excusant de son erreur - qui, je l'imagine, n'en était pas une : la mention obéissait à un impératif commercial; il était plus simple de vendre ce texte en le faisant passer pour un roman aux douanes de la littérature. La fin des années 1990 était encore une époque où le récit de soi et l'autofiction avaient mauvais genre, étaient considérés comme des genres impudiques, exhibitionnistes, narcissiques. De fait, et c'est intéressant pour un écrivain que la théorie des genres littéraires questionne, mon texte La Dernière année est à la fois un roman, dans sa première édition, et un texte sans mention générique, dans la seconde. Ce détail est important dans la mesure où il modifie considérablement l'horizon de lecture : les lecteurs du roman peuvent penser à bon droit que j'ai fictionnalisé en partie cette histoire, les autres doivent penser que tout ce que j'écris est entièrement autobiographique. Dans l'inscription de cette mention, c'est toute la distinction théorique entre l'autofiction et le récit autobiographique qui se joue.

8.

10 Je ne crois pas à la fonction magico-palliative de l'écriture du deuil. On n'écrit pas pour se débarrasser, pour faire le deuil, quand bien même écrire participe de ce travail de deuil, de ce processus de liquidation par le langage qui consiste, paradoxalement, à retrouver nos disparus dans l'univers du langage. Écrire ne console de rien. Écrire est une consolation dérisoire puisque l'on ne retrouve jamais que des spectres, des fantômes, une vie parmi les ombres. "Toute littérature suppose la perte de l'objet et son remplacement (je ne dis pas sa représentation) sous les espèces du mot », écrit Jean Starobinski dans La Relation critique. Écrire, c'est rester dans l'inconsolation.

9.

11 Pour la première fois depuis longtemps, La Fille à la voiture rouge fait resurgir l'image de mon père. C'est l'histoire d'une jeune fille de 20 ans qui, lorsque je l'ai rencontrée, m'a annoncé que, suite à un accident de voiture, elle avait conservé, comme séquelle, un hématome extradural sous le crâne, qui risquait de décider de sa vie à tout moment. 
C'est donc en condamnée, en jeune fille sursitaire que cette jeune fille est entrée dans mon cœur et m'a fait revivre une douleur enfouie, celle de perdre mon père. Les deux douleurs sont associées dans le roman qui, dans sa première partie, participe de la littérature de deuil.

\section{NOTES}

1. Philippe Vilain, Le Renoncement, Paris, Gallimard, 2001 ; L'Été à Dresde, Paris, Gallimard, 2003 ; Paris l'après-midi, Paris, Grasset, 2006 ; Faux-père, Paris, Grasset, 2008 ; La Femme infidèle, Paris, Grasset, 2013 ; Une idée de l'enfer, Paris, Grasset, 2015 ; La Fille à la voiture rouge, Paris, Grasset, 2017. 2. J. Lecarme, « Philippe Vilain, La Dernière Année », La Faute à Rousseau, nº 22, octobre 1999.

3. Michel Butor, «Une autobiographie dialectique », Répertoire, Paris, Éditions de Minuit, 1960, p. 270.

4. Simone de Beauvoir, La Force de l'âge [1960], Paris, Gallimard, coll. « Folio », 1986, p. 12.

\section{RÉSUMÉS}

Philippe Vilain se penche ici sur la relation originelle et forte de son écriture avec le deuil. Il revient sur le rôle de la mort de son père et de son statut d'orphelin, notamment dans La Dernière année.

Philippe Vilain examines here the original and strong relationship of his writing with mourning. He comes back to the role of his father's death and his status as an orphan, particularly in La Dernière année.

\section{INDEX}

Mots-clés : deuil, écriture, père, orphelin, écrivain, littérature

Keywords : mourning, grieve, death, orphan, writing, literature

\section{AUTEUR}

\section{PHILIPPE VILAIN}

Philippe Vilain est écrivain. Il a publié treize romans aux éditions Gallimard et Grasset (dont Pas son genre, adapté au cinéma par Lucas Belvaux) et une dizaine d'essais sur la littérature contemporaine dont L'autofiction en théorie (éditions de la Transparence); Dans le séjour des corps. Essai sur Marguerite Duras (éditions de la Transparence) ; La littérature sans idéal et La Passion 
d'Orphée (Grasset).

Il dirige la collection « Narratori Francesi Contemporanei » aux éditions Gremese International à Rome. 